\title{
ENDOMETRIOSIS AS A CAUSE OF INTESTINAL OBSTRUCTION \\ A Report of Two Cases
}

\author{
By Patrick G. Collins, M.Ch. (N.U.I.), F.R.C.S. \\ Senior Surgical Registrar, Derbyshire Royal Infirmary
}

Since Sampson (192I) described a case of endometrioma of the sigmoid colon, increased interest has been taken by surgeons in extragenital endometriosis. The site where this condition is most liable to give rise to complications is in the intestine where small and large bowel obstruction may result from the cyclic haemorrhages around and in the endometrial glands and stroma. The end-result of this process is a profuse fibroblastic reaction and cicatrization probably due to tissue response to free haemosiderin analagous to the cirrhotic liver that may occur in haemosiderosis. This leads to constriction of the bowel lumen, often in napkin-ring fashion. Obstruction may also occur due to encroachment on the bowel lumen of a mass of submucous endometrial gland tissue, designated ' an endometrioma,' without actual constriction of the bowel. This latter condition has a prediliction for the sigmoid colon. Occasionally, acute kinking and volvulus of the small bowel may occur due to dense adhesions caused by endometriosis (Grigsby, 194I).

When the small bowel is involved, in almost all cases the obstructive process is in the terminal ileum. Only in one of the reported cases was the obstructive process $60 \mathrm{~cm}$. above the ileo-caecal valve, and the case presented as a fish-bone perforation of the small bowel above the site of endometrial involvement of the ileum (Gale, I 93 I). Many of the patierits with ileal involvement have been diagnosed pre-operatively as having acute appendicitis (Colcock, I950; Clark I95 I, et al.,) One case was diagnosed as torsion of the pedicle of an ovarian cyst, and at laparotomy the ileal lesion was found to have caused an ileo-ileal intussusception (Cunningham and Viner Smith, 1948).

The rectum is the commonest site of large bowel invasion. This is usually due to direct spread of the endometrial process from the pouch of Douglas, or from a 'chocolate cyst' of the ovary into the rectal wall. Obstruction due to rectal involvement is rare, however, though in two of the three cases recorded by Graves (1927) the lumen of the rectum was obstructed. This is due to the anatomical fact that the diameter of the rectal ampulla is relatively large, and this is obvious to the surgeon when an anterior resection of the rectum for carcinoma is being performed. On the other hand, when the sigmoid colon is involved by the endometrial process, obstruction is much more liable to occur, and endometriosis at this site must be considered in the differential diagnosis of carcinoma of the sigmoid in women.

The purpose of this paper is to describe two further cases of endometriosis of the intestine which caused obstruction, the first in the ileum and the second in the sigmoid colon, and to discuss some points chiefly gleaned from the literature that may help in diagnosing and treating these patients.

\section{Case Reports}

Mrs. E.R., aged 40, was admitted to the Derbyshire Royal Infirmary in August 1955, complaining of central and lower colicky abdominal pain of 24 hours' duration. She had vomited several times following the onset of the pain. Her period had commenced a day before her symptoms developed, and although she had been subject to severe dysmenorrhoea since her middle twenties, she had not vomited previously during menstruation. Her bowels were regular, but had not been opened that day, though she had passed a little flatus. There was no urinary disturbance. She had one child, a normal delivery. There was no history of abortion. A history of dyspareunia had not been recorded.

On admission her temperature was $98.6^{\circ} \mathrm{F}$., pulse rate 1 i 8 per min. Her tongue was coated and foetor oris was present. She looked well nourished and was not obviously dehydrated. Her blood pressure was $150 / 90 \mathrm{~mm}$. mercury. 


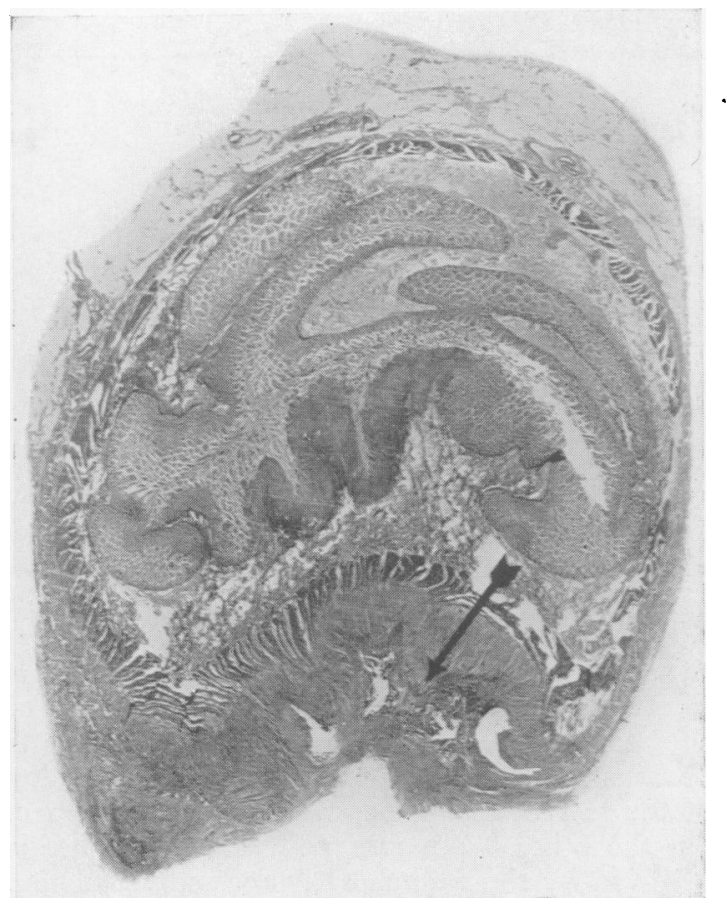

Fig. 1.-A cross section of ileum showing endometrial glands in its outer longitudinal muscle layer. Haematoxylin and eosin $\times 8$.

The abdomen was slightly distended and moved reasonably well with respiration, but there was marked direct tenderness in the lower abdomen, most marked in the right iliac fossa. Rebound tenderness was also present in the right iliac fossa.

Pelvic examination revealed no pelvic masses, but tenderness was noted in the pouch of Douglas. The presence or absence of bowel sounds was not recorded.

Laboratory Findings. White blood count $\mathrm{I}_{4}, 85^{\circ}$, polymorphonuclears 90 per cent., lymphocytes 8 per cent., monocytes 2 per cent. Urinalysis was not remarkable; there were no pus cells or organisms present in the urine on microscopic examination.

A tentative diagnosis of acute appendicitis was made, but as there was some doubt about this, laparotomy on the same date was performed through a right paramedian incision.

Laparotomy Findings. On opening the peritoneal cavity, some blood-stained fluid was noted. A loop of ileum about $12 \mathrm{~cm}$. long, extending to within $4 \mathrm{~cm}$. of the ileo-caecal junction, was found indurated, thickened and twisted on itself. The small bowel above this point was distended and obviously obstructed. The appendix was retrocaecal in position and did not appear inflamed.

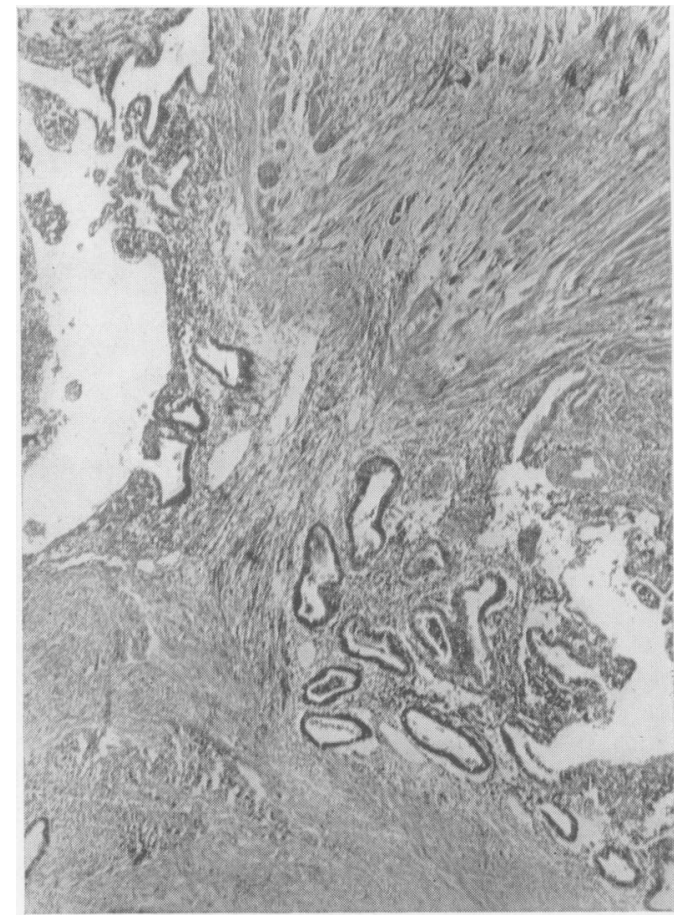

FIG. 2.-Photomicrograph of area marked by arrow in Fig. I, showing endometrial glands and stroma iro more detail. Haematoxylin and eosin $\times 60$.

The uterus, both Fallopian tubes, and the right ovary appeared normal, but the left ovary was slightly enlarged and firmly adherent to the left side wall of the pelvis.

Diagnosis was thought to rest between regional ileitis and carcinoid of the ileum. The glands in the ileal mesentery were small and few in number. About $25 \mathrm{~cm}$. of terminal ileum was resected and a side-to-side ileo-caecal anastomosis established. The appendix was also removed.

The abdomen was closed without drainage and subsequent recovery was uneventful. The patient is well to date. Pathological examination revealed a $24-\mathrm{cm}$. specimen of ileum containing a small perforating lesion closed by adhesions $4 \mathrm{~cm}$. from one end, and a smaller non-penetrating lesion near the other end of the specimen. Histological examination revealed endometrial glands and stroma in the muscle wall of the ileum (Figs. I and 2). The appendix also contained multiple small endometriomata.

Mrs. M.W., aged 48 , was admitted to the Derbyshire Royal Infirmary in November 1955 complaining of bouts of lower abdominal colicky pain of two years' duration. During the sixmonth period prior to admission these attacks of pain had increased in frequency and severity. 


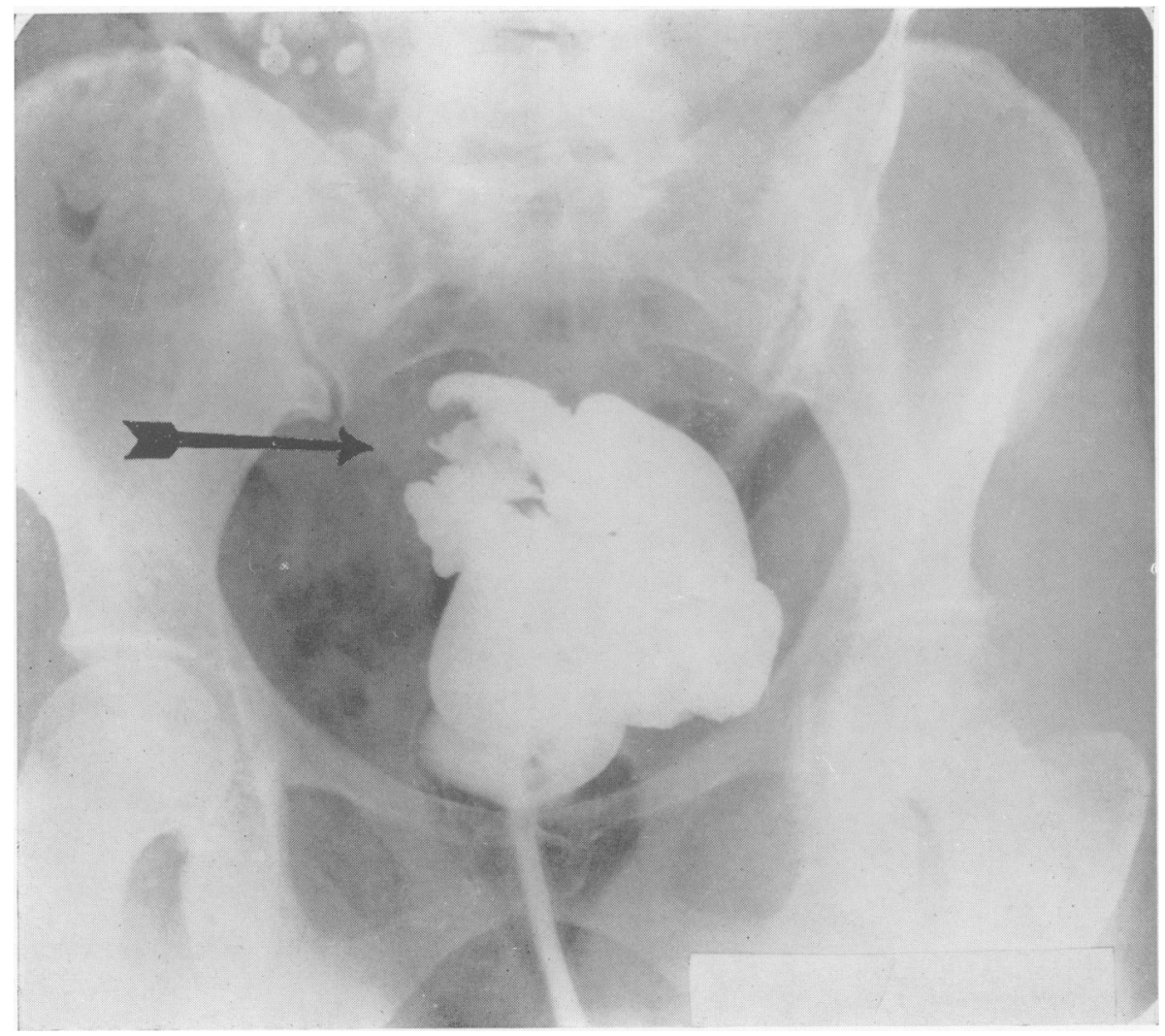

FIG. 3.-Radiograph of a barium enema showing a constant, irregular filling defect in the sigmoid colon

No vomiting occurred, but alternating bouts of constipation and diarrhoea of recent onset were causing her worry and acute discomfort. She had not lost weight. There was no marked urinary disturbance and she had never seen blood in the stools.

Previously she had been operated upon twice. In August I948 a total hysterectomy and left salpingo-oophorectomy was performed for a chronic vaginal discharge. At this operation some brown fluid was expressed from the left ovary and it was considered by the surgeon to contain a very small 'chocolate cyst.' There were several small nodules also present in the pouch of Douglas which were considered to be endometriomata. The right ovary appeared normal and was not removed.

Pathological and histological examination of the uterus, left tube and ovary was not remarkable. The left ovary was described as containing appreciable numbers of small follicular cysts. The clinical diagnosis, therefore, of endometriosis of the left ovary was not confirmed histologically.

The second operation was in March I953, when an anterior colporrhaphy was performed.
Prior to the hysterectomy in 1948 , her periods had always been regular, but for many years she had experienced severe pre-menstrual and menstrual backache. She had two children, both normal deliveries. There was no history of abortion or dyspareunia. Examination on admission revealed no physical abnormality apart from the presence of a right paramedian abdominal scar: there was slight deep tenderness in the right iliac fossa. Pelvic examination revealed no pelvic masses or tenderness. The temperature was $98.4^{\circ} \mathrm{F}$., pulse rate 90 . The blood pressure was I30/90 mm. mercury.

Laboratory Findings. Haemoglobin was $14.94 \mathrm{~g}$. per $100 \mathrm{ml}$., white blood count was 19,900, 79 per cent. polymorphonuclears, 9 per cent. old metamyelocytes, I I per cent. lymphocytes and I per cent. monocytes. There was no obvious cause for this elevated white blood count. Two out of three specimens of faeces tested for occult blood were positive. Sigmoidoscopy revealed a constricted area at about $18 \mathrm{~cm}$. The instrument could not be advanced beyond this point. No mucosal ulceration was noted. Radiological examination by barium enema demonstrated a 


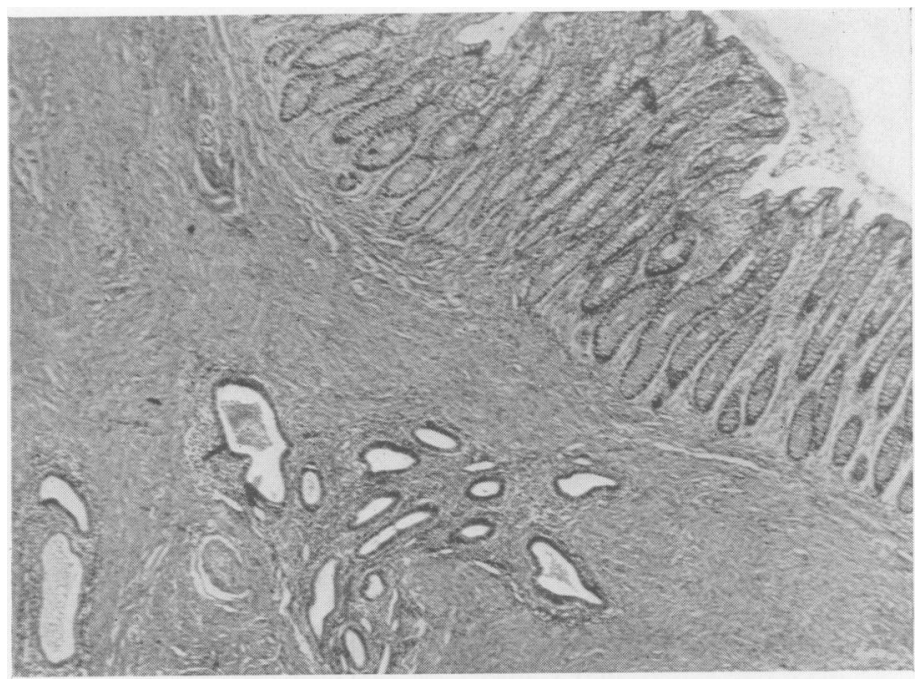

FIG. 4.-Photomicrograph of the wall of the sigmoid colon showing endometrial glands and stroma in the submucosa. Haematoxylin and $\operatorname{eosin} \times 60$.

constant irregular filling defect in the sigmoid colon (Fig. 3).

The pre-operative diagnosis was carcinoma of the sigmoid colon. At laparotomy, an indurated mass was discovered low down in the sigmoid colon near the pelvi-rectal junction, which was definitely causing a partial large bowel obstruction. No glands were palpated in the meso-sigmoid and there were no obvious secondaries palpated in the liver. The pelvis contained many dense adhesions and the right ovary was not visualized. The indurated mass in the sigmoid colon was resected and an end-to-end anastomosis of the large bowel performed over a rectal tube. The appendix was also removed as it was thought that it may have been responsible for the raised white count discovered pre-operatively.

Post-operative recovery was uneventful and the patient remains well to date.

Pathological examination of the resected colon showed a specimen $17 \mathrm{~cm}$. long. A 'tumour' involved $3 \mathrm{~cm}$. of the specimen. Histological examination revealed this 'tumour' as an endometrioma (Fig. 4). There was no evidence of mucosal ulceration, but the mucosa overlying the ' tumour' was adherent to the deeper tissues.

\section{Discussion}

I do not propose to give a comprehensive account of endometriosis as it affects general surgery, as excellent accounts have already been published (Macleod, 1946; McGuff, I948; Clark, 195 $\mathrm{I}$, et al.). It is not my wish to discuss the various theories advanced in an endeavour to explain the unique spread of endometrial gland tissue and its surrounding stroma to tissues of the body foreign to it. A good textbook of pathology will discuss this aspect of the condition. Macleod's paper (1946) is also admirable in this respect. As already mentioned, it is my plan to outline the incidence, symptoms and? signs of extragenital endometriosis as it affects the intestinal tract and to discuss diagnosis and treatment.

\section{Incidence}

In 1943 Jenkinson and Brown stated that endometriosis occurs in approximately 15 per cent. of all women during their active menstrual life. Fortunately, the condition is usually confined to the pelvic organs and rarely affects the intestine sufficiently to cause symptoms of obstruction. One feels, however, that in many cases where bowel is involved to a minor degree, the condition is never diagnosed and luckily the pathological process in the bowel wall regresses with the onset of the menopause in the majority of cases.

That symptoms of obstruction can occur in the post-menopausal period due to endometriosis is evident from case histories quoted by McKittrick (1937) and Colcock (1950). Colcock's two patients were 67 and 69 respectively when they presented with intestinal obstruction due to endometriosis. McKittrick reported a patient of 64 who developed intestinal obstruction, due to this condition, I4 years after the menopause. He also found in the literature four other instances of patients who developed large bowel obstruction 
due to endometriosis who were all in the postmenopausal age group. One may draw a comparison between post-menopausal endometriosis of the bowel and the healed tuberculous kidney lesion following adequate therapy with antituberculous drugs. The source of the irritant substance had been removed in both cases: in endometriosis of the intestine, the cyclic haemorrhages within the bowel tissues have ceased with the loss of oestrogenic hormonal stimulation from the ovaries: in tuberculosis of the kidney the lipoid material derived from the tubercle bacillus diminishes with death of the organism. Despite this fact, sometimes fibrosis and contraction of tissue proceeds as the fibroblasts age, and in the intestine may cause obstruction necessitating resection of a stricture. Likewise in the kidney, the pelvi-ureteric junction or calycine necks may contract and ultimately obstruct the kidney sufficiently to necessitate its removal.

In 1937 Cattell, at the Lahey Clinic, reviewing I04 patients with endometriosis, found that 17 , or 16.3 per cent., had involvement of the rectum or sigmoid colon. Two of these had almost complete large bowel obstruction at sigmoid level, whilst $\mathrm{I} 2$ others had varying degrees of obstruction. A further 307 patients with endometriosis were reviewed, also at the Lahey Clinic, by Colcock and Lamphier in 1950; of these, 213 patients were operated upon and 39 , or 18.3 per cent., were found to have endometriosis of the rectum, recto-sigmoid and/or small intestine. Of this group of 39 cases, I4 presented with varying degrees of bowel obstruction.

McGuff and his associates in 1948 found that from 1920 to 1946 , inclusive, only 48 case records were found in the surgical files of the Mayo Clinic in which the diagnosis 'endometriosis of the bowel' was made by a pathologist. Only in a third (I6) of these cases was the pathological material removed to relieve obstruction: the small bowel was obstructed in 3 cases only, the remaining $\mathrm{I} 3$ being obstructed in the sigmoid or rectum.

In I95 I Clark could only collect 27 cases of small bowel obstruction due to endometriosis from the literature; to these he added 3 cases of his own which had been seen in approximately 80,000 surgical pathology specimens.

Masson (1935) reported only 2 cases affecting the ileum in a total of 599. Counseler and Sluder (I945) found 20 cases involving the ileum in 754 patients showing endometriosis in a total of 1,434 locations. Keene and Kimborough (1930), on the other hand, in their I i 8 cases of endometriosis did not find the small intestine affected in any.

From these figures one can deduce that symptomatic involvement of the bowel is rare in endo- metriosis, and that large bowel obstruction is relatively commoner than small bowel obstruction in this condition. Despite this rarity, however, the occurrence of this process occasionally is of sufficient importance to justify its inclusion among the important benign lesions of the alimentary tract.

It is interesting to note that the average age of the patients in whom obstruction occurred is similar in Colcock's and McGuff's series, e.g. 39.5 years.

\section{Symptoms}

The patient usually presents herself to her doctor with a history of ' co-menstrual' colicky abdominal pain of anything from months to several years' duration. In small bowel involvement, the onset of obstruction may be so acute, however, that a previous history of ' co-menstrual' colicky abdominal pain may not be recorded. This occurred when Case I presented herself. Vomiting is usual in obstruction of the small bowel, but infrequent in cases of large bowel involvement, unless the obstruction is almost complete.

The patient is often relatively or absolutely sterile. In McGuff's series of 12 married women, more than half the patients had never been pregnant, and at least two-thirds of the remainder had never carried a foetus to full term. In Colcock's series numbering I 3 married women, 8 of the 13 were childless and 3 of the remaining 5 had only one child.

Dysmenorrhoea is usually of the acquired type and the percentage of patients complaining of this classical symptom of endometriosis was exactly similar in both the McGuff and Colcock series, e.g. 50 per cent.

In both series dyspareunia was rare. Weight loss was a variable symptom: whilst in some series there was no weight loss, in others about a third lost over a stone. This could be attributed to the degree of obstruction and the length of time between the onset of severe symptoms and the patient's visit to hospital.

Most of the patients gave a history of constipation, but in those with colon and or rectal involvement, alternating constipation and diarrhoea often occurred. Case 2 presented with this complaint as one of her major symptoms.

If the rectum is grossly involved, and usually the recto-vaginal septum and pelvic peritoneum is involved also in these cases, dyschezia, proctalgia and pain in the perireum is often the case. Sacral backache is also a predominant symptom and this may coincide with the attacks of colicky abdominal pain just before or during the periods. Blood loss in the stool is rare: only 3 out of McGuff's I6 patients had blood in the stools, 
and one of these had a rectal carcinoma present as well as an endometrial stricture of the sigmoid. To be of significance, blood in the stools should be 'co-menstrual' and rectal neoplasm must be excluded. The reason that so few cases have blood in the stools is obvious when it is noted that only I case out of McGuff's I 6 cases showed evidence of mucosal ulceration, and this only on microscopic examination.

\section{Diagnosis}

These symptoms, with one or more of the following findings, should make the clinician suspect endometrial involvement of bowel :-

(I) The presence of endometrial tissue elsewhere in the body, e.g. in the umbilicus or the perineum or in a laparotomy scar, or a history of endometrial tissue being removed during a previous operation from the inguinal region or genital organs.

(2) On vaginal examination the presence of dark blue endometrial cysts or nodules in the vaginal vault.

(3) On pelvic examination the presence of tender fibroids which are really 'adenomyomata,' the result of infiltration of the uterine muscle by the endometrial glands; the presence of bilateral cysts should also make the clinician suspect ' chocolate cysts' of the ovaries.

(4) On sigmoidoscopy the absence of mucosal ulceration; the mucosa, however, may be puckered and distorted, the bowel may be strictured or contracted and thus simulate diverticulitis: biopsy usually shows only normal mucosa.

(5) A radiograph of the colon following barium enema often shows a filling defect which in McGuff's series was inconstant, but in Case 2 was constant. Sometimes the area of bowel involvement is tender to deep palpation and is often fixed in position.

(6) Finally, the frequency with which the diagnosis of endometriosis of the bowel is made by the surgeon or clinician varies with their 'threshold of suspicion' (McGuff, I948). If in these two cases suspicion had been aroused by the previous symptoms, in Case $I$ the adherent ovary may have been the final clue; in Case 2 the operation report on a possible small ' chocolate cyst ' being removed at a previous operation, and the fact that there were nodules similar to endometrial nodules in the pouch of Douglas should have stimulated the surgeon to request a frozen section. That the histologist reported the left ovary as containing only follicular cysts did not mean that it did not contain a small ' chocolate cyst' from which the contents had been evacuated. The histologist can easily miss endometrial tissue in an ovary if the cyst is small, unless his attention is drawn to endometriosis by the surgeon and serial sections of the ovary are cut. Frozen section also of the intestinal lesion at operation can clinch the clinical diagnosis of obstruction due to endometriosis.

\section{Treatment}

Treatment is surgical. One must remember, however, that the lesion is under ovarian hormonal control and that regression of the endometrial process will take place if bilateral oophorectomy is performed. However, each case must be treated individually, and the final procedure must depend upon the patient's age, her desire to become pregnant, the degree of obstruction and the extent of pelvic endometriosis. The extreme discomfort, mental and physical, which may follow an artificial menopause by removing the ovaries from a young woman of 30 or thereabouts may be too great a price to pay to lessen the risk of further attacks of intestinal obstruction even if endometriosis is widespread. The following points may help to decide the best treatment in any individual case :-

(I) If the patient is extremely ill with gross abdominal distension due to obstruction, colostomy or ileo-transverse colostomy is all that may be possible with safety. One case has beenreported where the latter procedure was carried out (Morrin, 1942).

(2) If the patient is fit, resection of the involved portion of bowel and anastomosis is the treatment of choice. Occasionally, local excision of an endometrioma from the colon wall with local repair of the defect may be possible (McGuff, I948, Case 12).

(3) If widespread pelvic endometriosis exists and the patient is over 40 , bilateral oophorectomy should be seriously considered as well as resecting the bowel. Several cases have been reported where bilateral oophorectomy alone or hysterectomy and bilateral oophorectomy without surgery to the involved obstructed intestirie has completely relieved symptoms (Goodwin, r934; Dougal, I948, et al.). One must mention, however, that in these cases the obstruction was of a very low grade.

(4) Finally, radiation therapy should be reserved for cases of recurrent low-grade partial obstruction, where the diagnosis of endometriosis has been made with certainty at a previous operation and where the patient is near the menopause and does not wish to undergo a second surgical procedure to remove her ovaries. Even here, radiation is dangerous, as the low-grade obstructive process may be converted into an acute obstruction by tissue reaction to deep $\mathrm{X}$-rays. 


\section{Summary}

(I) Two cases of endometriosis of the bowel causing intestinal obstruction are reported.

(2) The incidence, symptoms, signs and treatment of these cases are discussed with reference to the available literature on the subject.

(3) More of these cases will be diagnosed at operation, and the diagnosis clinched by frozen section if the surgeon suspects the existence of the condition pre-operatively.

\section{Acknowledgments}

I should like to extend my thanks to Mr. J. R. Ratcliffe and Mr. F. G. Hollands for permission to publish details of these cases. I should also like to thank Dr. G. R. Osborn for the photomicrographs and Dr. G. Q. Chance and Mr. L. Stiles for the radiograph.

\section{REFERENCES}

CATTELL, R. B. (1937), New Engl. F. Med., 217, 9.

CLARK, C. E. (1951), The Amer. Surg., 17, 145.

COLCOCK, B. P., and LAMPHIER, T. A. (I950), Surgery, 28, 997. COUNSELER, V. S., and SLUDER, F. S., Jr. (1945), Rocky Mtn. med.' '., 42, I89.

DOUGAL, D. (1938), Amer. F. Obstet. Gynec, 35, 373.

CUNNINGHAM, K., and SMITH, K. V. (1948), Brit. F. Surg., 36,50 .

GALE, C. (1931), Aust. N.Z. F. Surgery, 1, 323.

GOODWIN, W. H. (1934), Va. med. Mon., 61, 257.

GRAVES, W. P. (1927), Amer. F. Obstet., 13, 728

GRIGSBY, G. P. (I941), Sth. Surg., ro, 8.

JENKINSON, E. L., and BROWN, W. H. (1943), F. Amer. med. Ass., 122, 349.

KEENE, F. E., and KIMBOROUGH, R. A. (1930), Ibid., 95, I 164. MACLEOD, D. (1946), Brit. F. Surg., 34, 109.

MASSON, J. C. (1935), Ann. Surg., 102, 819.

MCGUFF, P., DOCKERTY, M. B., WAUGH, J. M., and RANDAL̈L, L. M. (1948), Surg. Gynec. Obstet., 86, 273.

MCKITTRICK, L. S. (1937), New Engl. F. Med., 217, 17.

MORRIN, F. J. (1942), Irish F. :weti. Sci., Sixtl. Ser. No. 198, 207.

SAMPSON, J. A. (1921), Arch. Surg., 3, 245.

\section{Books Received}

The Editorial Board acknowledge with thanks receipt of the following volumes. A selection from these will be made for review.

'Biology Staining Schedules for ist Year Students.' By R. R. Fowell, M.Sc. 5th Edition. Pp. 27. London: H. K. Lewis \& Co. Ltd. 1957. 2s. $6 \mathrm{~d}$.

'Materia Medica and Pharmacology for Nurses.' By J. S. Peel, M.P.S. 2nd Edition. Pp. 171, with I4 diagrams. Christchurch: N. M. Peryer Ltd. I $957.24 \mathrm{~s}$.

'Chronic Bronchitis in Newcastle-upon-Tyne.' By A. G. Ogilvie, M.D., F.R.C.P., and D. J. Newell, M.A. Pp. vii + I I5. Edinburgh: E. \& S. Livingstone Ltd. I957. I5s.

'Human Blood Coagulation and its Disorders.' By Rosemary Biggs, B.Sc., Ph.D., M.D., and R. G. Macfarlane, M.A., M.D., F.R.S. Pp. xxv +476 , illustrated. Oxford: Blackwell Scientific Publications. 1957. 42s.

'An Atlas of Muscle Pathology in Neuromuscular Diseases.' By J. Godwin Greenfield, M.D., G. Milton Shy, M.D., Ellsworth C. Alword, Jr., M.D., and Leonard Berg, M.D. Pp. ix + ro4, with 93 illustrations, many in colour. Edinburgh: E. \& S. Livingstone Ltd. I957. 45s.

'Modern 'Trends in Neurology.' 2nd Series. Edited by Denis Williams, C.B.E., M.D., D.Sc., F.R.C.P. Pp. xi + 374, with 79 illustrations. London: Butterworth \& Co. Ltd. 1957. 72s. 6d.

'Individual Differences in Night-Vision Efficiency.' By M. H. Pirenne, F. H. C. Marriott and
E. F. O'Doherty. Pp. vii +83 . London: H.M.S.O. 1957. 8s.

'Leukaemia and Aplastic Anaemia in Patients Irradiated for Ankylosing Spondylitis.' By W. M. Court-Brown, O.B.E., M.B., B.Sc., F.F.R., and R. Doll, O.B.E., M.D., F.R.C.P. Pp. vi + 135 . London: H.M.S.O. I957. Ios. 6d.

'Australasian Annals of Medicine.' Vol. 6. Journal of the Royal Australasian College of Physicians. Pp. 87, illustrated. Sydney: Royal Australasian College of Physicians. I 957. 20 s.

'Simulium and Onchocerciasis in the Northern 'Territories of the Gold Coast.' By G. Crisp, B.Sc., Ph.D., F.Z.S., F.R.E.S. Pp. xvi + I7r, with 5 maps and 54 illustrations. London: H. K. Lewis \& Co. Ltd. I956. 57s. 6d.

'The British Journal of Surgery.' Vol. XLIV. No. I 87. Pp. I I 2, illustrated. Bristol: John Wright $\&$ Sons Ltd. r 957. I 4 s.

'Your Baby - and You.' By Winifred de Kole. Pp. 221. London: Pan Books Ltd. 1957. 2s. 6d. 'A Synopsis of Surgical Anatomy.' By A. Lee McGregor, M.Ch., F.R.C.S. 8th Edition. Pp. xii +808 , with 766 diagrams. Bristol: John Wright \& Sons Ltd. I957. 32s. 6d.

'Nerves Explained.' By Richard Asher, M.D., F.R.C.P. Pp. 157. London: Faber \& Faber. I957. IOs. $6 \mathrm{~d}$.

'Recent Outbreaks of Infectious Diseases.' By 